Document downloaded from:

http://hdl.handle.net/10251/178261

This paper must be cited as:

Márquez Cañizares, JC.; Rojas, J.; Higuera-Trujillo, JL.; Muniz, G. (2020). An eye-tracking project in industrial design education: A case study for engaging in the research process. IEEE. 127-132. https://doi.org/10.1109/EDUCON45650.2020.9125143

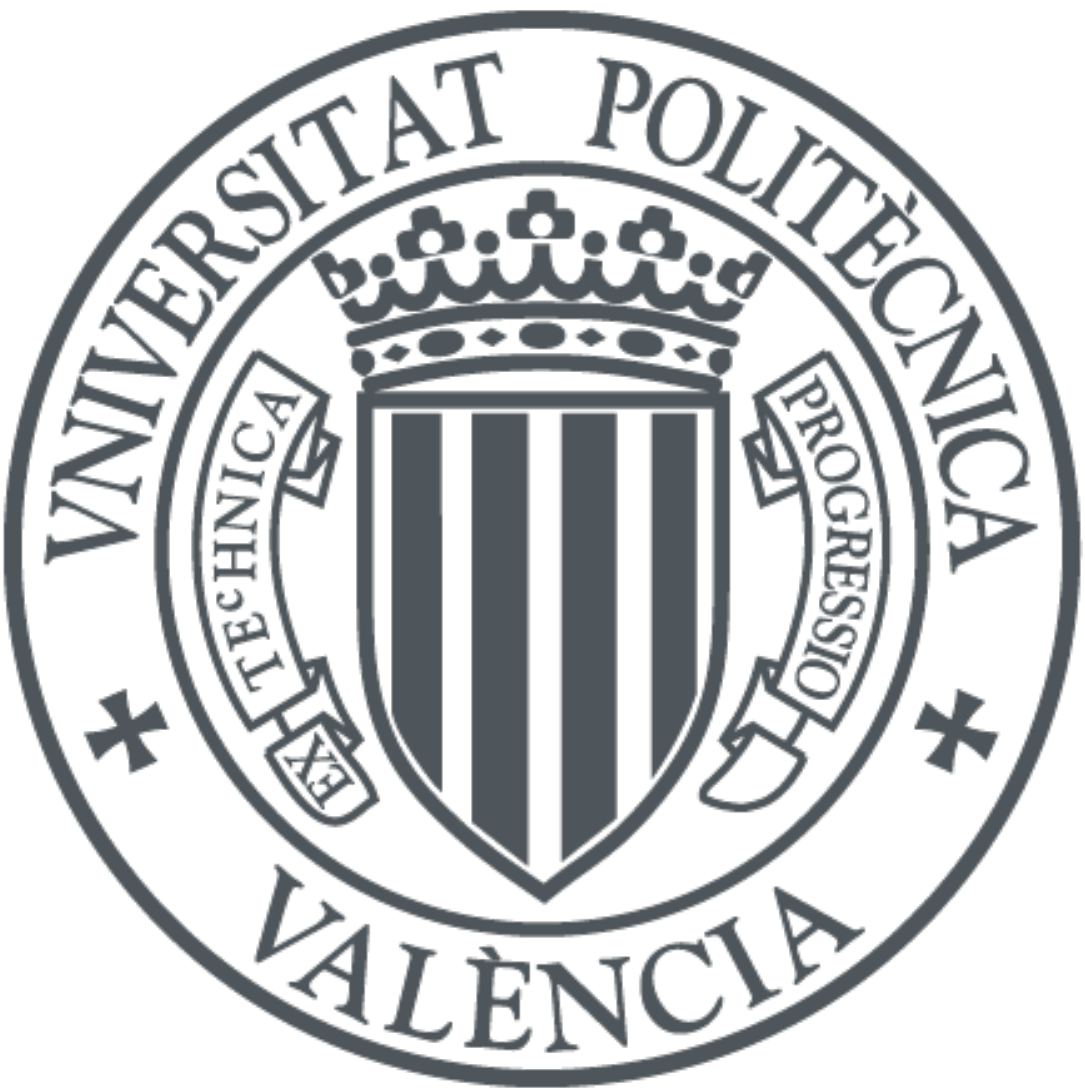

The final publication is available at

https://doi.org/10.1109/EDUCON45650.2020.9125143

Copyright IEEE

Additional Information 


\title{
An Eye-Tracking Project in Industrial Design Education: A case study for Engaging in the Research Process
}

\author{
Juan-Carlos Rojas \\ Escuela de Arquitectura, Arte y Diseño, \\ Writing lab, Teclabs, Vicerrectoria de \\ Investigacion y Transferencia de \\ Tecnologia \\ Tecnologico de Monterrey \\ Monterrey, Mexico \\ jcrojasl@tec.mx
}

\author{
Juan Carlos Márquez Cañizares \\ Escuela de Arquitectura, Arte y Diseño, \\ Writing lab, Teclabs, Vicerrectoria de \\ Investigacion y Transferencia de \\ Tecnologia \\ Tecnologico de Monterrey \\ Monterrey, Mexico \\ jcmarquez@tec.mx \\ Gerardo Muniz \\ Escuela de Arquitectura, Arte y Diseño \\ Tecnologico de Monterrey \\ Monterrey, Mexico \\ gerardo_muniz@tec.mx
}

\author{
Juan Luis Higuera-Trujillo \\ Institute for Research and Innovation in \\ Bioengineering (i3B) \\ Universitat Politècnica de València \\ Valencia, Spain \\ jlhiguera@i3b.upv.es
}

\begin{abstract}
The practice of design is constantly evolving; new technologies have become a support for the implementation of disruptive proposals in diverse disciplines, including design products. A Paradigm shift are present in the design and engineering education related with support technologies and developing new products. The objective of this work is to present the novel process of a design project that incorporates a creative and objective process for designing and validating products in order to attract, engage and retain talent in design and engineering courses for research and technology implementation. The challenge was a project for create an novelty industrial tool board with a minimum number of tools validated by Eye-tracking (ET) technology. The ET technology is based on the study of eye movement, which provides an objective indicator of where a person's overt, and typically centered, attention is focused. Twenty-eight students from the third year of Industrial Design Bachelor's program were involved in this academic course and used a product design methodology to implement the technology and dynamics of the ET. The results of this education project revealed a novel dynamic in design education. The results reveled an improved interest in research and technology implementation. Students perceived the relevance of ET technology in a fundamental phase of product design. In addition, the students shared their enjoyment and interest in reusing this technology in similar processes. The students' perception of factors, such as utility, novelty and relevance of this technology, in their design processes was positive. Finally, the novel process became familiar to the students, even if it was their first-time using ET technology. This work reveals how technology becomes a fundamental part of the process and how to guide students to integrate rigid and meticulous processes in design products without neglecting the creative process.
\end{abstract}

Keywords- Design, Education, Eye-tracking, Industrial products, Student attraction.

\section{BACKGROUND}

The practice of design is constantly evolving; new technologies support the implementation of disruptive proposals in diverse disciplines, such as design. This work focused in two relevant aspects for improving teaching and learning experiences in engineering education and for attracting, engaging and retaining talent in design and engineering courses.

The first relevant aspect is the paradigm shift of design teaching for students in product engineering or similar degrees. Alain Findeli [1] proposed an approach based on extensive research in a new rethinking of design and design education. The author's approach incorporates science and technology in the creative process as a ground for a new and more effective structure for design, following a growing emphasis in the necessity to educate future generations using systems thinking [2]. The evolution of design education is correlated with engineering education and aspect such as problem-solving methodologies and creative dimensions [3]. The discussion regarding the differences between design thinking and engineering thinking is latent, however there are elements they share, such as product development [4] and process that must be considered to find common practices. In recent years, practitioners have integrated in industrial design currulum a creative and reflective activities to training students for a specific and non-specific knowledge support by active activities in workshops or laboratories. [5]. In the relationship between the designer and the engineer, a tension in the way of thinking and their education is latent [6] due to emotional and functional aspects that each area defends. However, Wölfel [7] argues that the difference between the knowledge of these two areas is that the designers focus on new and innovative designs, while the engineers focus on the adaptive and detailed design, which creates a natural and motivational collaborative dynamic. Finally, a solution to improving the pedagogy design is to improve systematic thinking and specific dynamic practices in projects in order to empower students' hard and creative skills [3].

The second relevant aspect mentioned above is the incorporation of a technology that contributes a change into the teaching, development and collaboration of design projects. This work will show how industrial design students were 


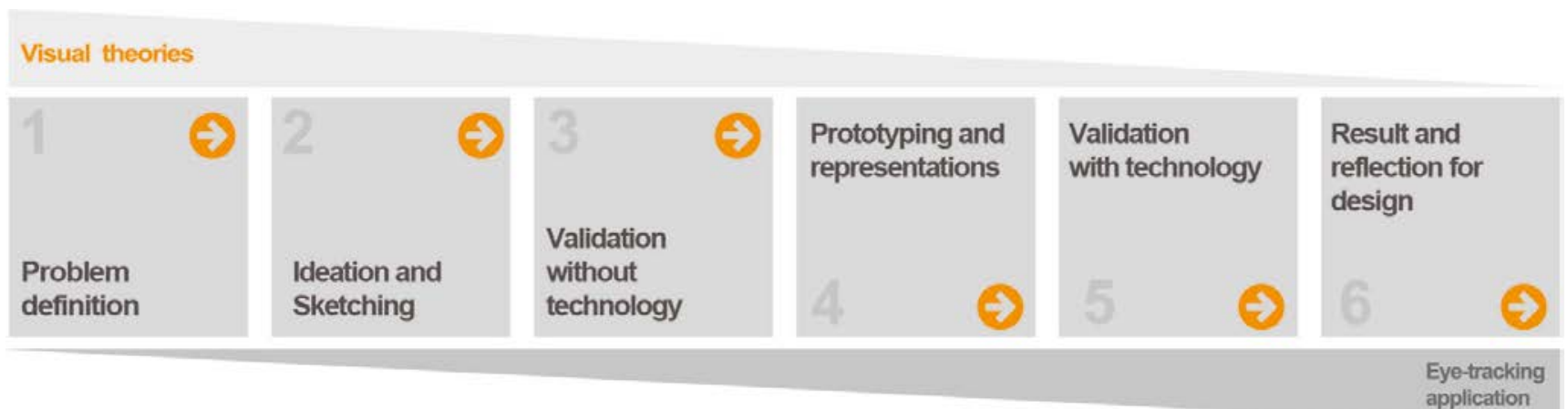

Fig. 1. Design project methodology scheme used in the course.

introduced to a novel project to improve the systematic thinking and creative process that included the use of technologies for the validation of visual properties and research analysis. Eye-tracking (ET) technology is based on the study of eye movement, which provides an objective indicator of where a person's overt, and typically centered, attention is focused [8-9]. In the process of product creation, there are many design principles that can be validated through ET technology, and the students could notice the importance of visual attention and the specific elements that can attract the interest that this represents in the decision making of users [10]. This work considers the relevance of visual attention for the design of better products. An example of the relevance of visual design and its characterization for correct understanding are road signs. They should be clear, simple and easy to understand by anyone [11] and use symbols, colors and shapes correctly. For this work, the project approach to the design of a tool board can create a systematic and technology-driven process. The implementation of ET and its relationship with the study of objects and human capabilities is relevant. The gaze capability to interact with the environment [12] acilitates the perception of affordances and elements present in scenes of interest. In the case of tools, visual exploration focuses on usability and functional components, which were exposed in an in-depth study on the visual exploration of tools [13]. Finally, ET technology provides access to crucial aspects of cognitive processes, such as attention, memory, decision making and cognitive control [14], as well as fundamental elements in the planning or design of a product that directly impacts an operator or user.

In conclusion, this work will describe how a novel design process with ET dynamics can improve aspects that should be considered in engineering and design education practice. This paper considers key issue regarding with project develop and perceived benefits for students.

\section{RESEARCH QUESTIONS}

RQ1: How can a design and ET project cultivate more interest in research and technology?

RQ2: How is the acceptance of ET technology in a product design project?

RQ3: How do students evaluate the utility, novelty and relevance of ET technology in their projects?

\section{AIM}

This research initiative seeks to observe, describe and analyze the student's perception, engagement and acceptance of technologies in the creative process for improved design education. The definition of the project or challenge for the students is to design an industrial tool board with a minimum number of tools and to validate the design purpose through ET technology. The main objective of this work is to engage students in understanding the relationship of the visual attention to the details of the product and the user's behavior once exposed to products or services and how they can research them.

\section{METHOD}

\section{A. Situating the case:}

At our university, an initiative was started for students of industrial design and related areas that provides access to an experiential space for use of technologies, physiological measurements and immersive visualization tools. This initiative is called the Research, Experience \& Design Laboratory (REDlab). 


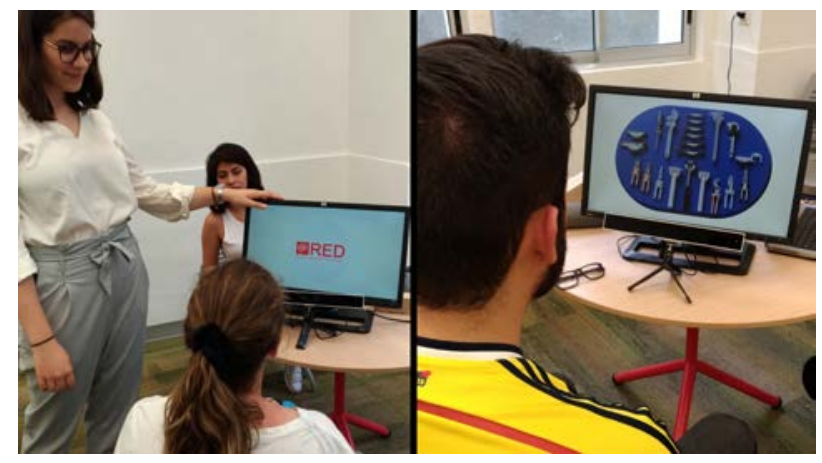

Fig. 2. Students at REDlab using ET technology to validate tool boards.

\section{B. Design Project Methodology}

Twenty-eight design students from the third year of the Industrial Design bachelor's program were involved in this academic course, wherein a product design methodology created exclusively to implement the technology and dynamics of the ET was utilized. The students answered a satisfaction survey in order to measure the overall experience of the ET project at the end of the semester (eight-week project). The project methodolgy created for develop a novelty tool board was divided intro six steps (see Figure 1):

1) Problem definition: The teacher presented the challenge to the students. After, they started with research on similar products and then reviewed the Gestalt literature theory and design principles for visual attention.

2) Ideation and Sketching: The second step of the methodology was a creative process. Students created a series of ideas in a brainstorming exercise and sketched the best ideas. After a synthesis process, the students used three ideas in the next step, the validation exercise.

3) Validation without technology: Selected ideas were sketched in a 1:1 scale to perform the first exercise that utilized a basic principle of ET technology. The fixation and gaze path were simulated in the 1:1 sketching using threads. Students recruited 30 participants to perform a searching task in the sketching tool board representation.

4) Prototyping and representations: Information from step 3 was taken to select a unique idea. Students modeled and rendered a photorealistic tool board to prepare visual elements for the ET evaluation. An example of some of their results are shown in Figure 4.

5) Validation with technology: Students created a research protocol with the visual elements (four perspectives) and three tasks to perform in the tool board. In the REDlab, 35 participants were invited to perform the protocol using Gazepoint ${ }^{\circledR}$ hardware and software (see Figure 3).

6) Results and reflection for design: Finally, the students collected the information and compared the results of the participants. An analysis process was made of the results of the gaze behavior and the impact of the design tool board upon the participants. 


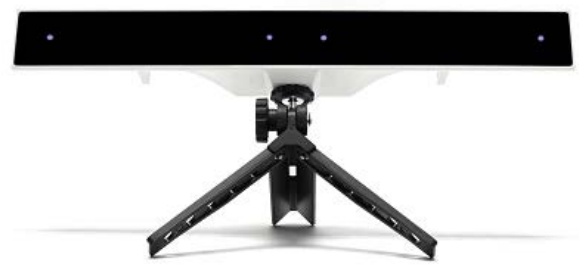

Fig. 3. Eye-tracking Bar, 150 hrz, Gazepoint ${ }^{\circledR}$.

\section{Student participants}

This paper utilized information from two courses taught in the Industrial Design bachelor's programs. Twenty-eight students (women $=21$, men $=7$ ) completed the course in spring-summer and fall-winter 2019 semesters (see Figure 2).

At the end of the project, the students presented a final report that included the process followed and the corresponding analyses extracted from ET. Then, students answered a survey, which was divided into three sections with an exclusionary answer (yes/no), two multiple choice and three questions using a 1 to 5 Likert scale, where 5 is the highest rate. The questions, designed to validate the impact of the project, are described below:

Three questions were asked at the beginning of the survey to understand the position of the students' perception about the ET project experience:

1. Do you consider what you know about design product process to be foundational knowledge?

2. Do you believe the use of ET technology reinforces the design product process?

3. Would you recommend employing ET technology in future design product processes?

Next, two multiple-choice questions assessed whether the students had identified the contribution of the ET project experience:

4. Which phase of the design product process can ET technology have a strategic impact?

a) Exploration/Ideation, b) Definition/Design

c) Develop/Tests, d) Deliver/Feedback

5. Do you think a design product process should be more an objective process or a creative process in order to create better products?

a) Yes, b) both, c) No
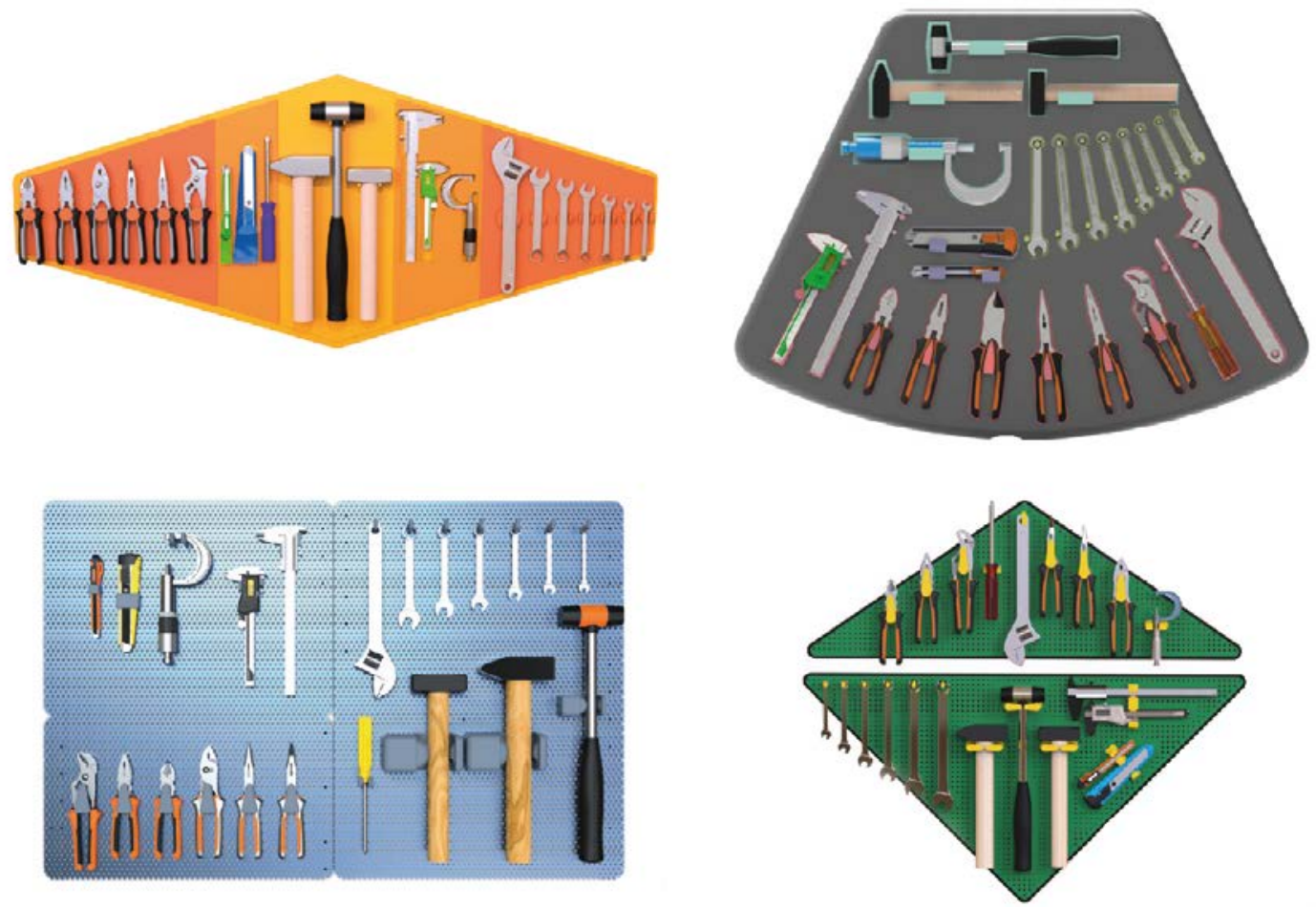

Fig. 4. Example of tool board created in the course. 
Finally, the last questions using a Likert scale to quantify the perception of three factors measure the impact of the ET project experience:

6. How do you evaluate the utility of the ET technology used in the course?

7. How do you evaluate the novelty of the ET technology used in the course?

8. How do you evaluate the relevance of the ET technology used in the course?

\section{DATA ANALYSIS AND RESULTS}

The analysis of the data is divided into three parts or observations in order to detect the experience and perception aspects of the ET project. The first analysis examined the options of the yes/no and multiple-choice questions regarding the ET experience of the project. The second analysis calculated the statistical results for the mean and standard deviation of the Likert scale questions, which measured opinion data regarding the utility, novelty, and relevance factors of the ET technology in the course. The final analysis contrasted the mean of the question results regarding course experience, which was obtained from the three Likert scale questions.

The first analysis revealed two outcomes. 1) students had a positive opinion of ET technology used in the design product process. They claim (96.4\%) that this ET technology reinforces the process. In addition, they affirm (96.4\%) to recommend the ET technology for next projects. 2) In multiple-choice question 4 and 5. Students thought that ET technology had a major strategic impact on Develop/Tests (70\%) before the other phases. Likewise, they concluded that design process must be "Both"(71.5\%) processes, a creative and objective. The results are shown in Figure 5.

In the second analysis examining the findings from the Likert scale questions, students can quantify their perception of elements that can be relevant for attracting and engaging. The results for utility (mean $=4.96$ ), novelty (mean $=4.86$ ), and relevance (mean $=4.89$ ) were positively evaluated and display a low variability in the students' opinions $(0.189$ to 0.448$)$. The data are shown in Table I.

Statistical analysis was performed using SPSS 17.0 for Windows ${ }^{\mathrm{TM}}$ (IBM SPSS Inc., Chicago, IL, USA). An ANOVA was applied in the last analysys to examine the contrast between the strategic multiple-choice questions and the opinion evaluation regarding the perception experience of the project. A complete table of descriptive and statistical results is presented in Table 2. The test revealed that two of the six variables present a significant value $(<0.05)$. For "Which phase of the design product process can ET technology have a strategic impact?" question, only the utility factor showed a significant value ( $\mathrm{p}=0.043)$. Finally, for "Do you think a design product process should be more an objective process or a creative process in order to create better products?" question, only the relevance factor showed a significant value $(\mathrm{p}=0.007)$.

TABLE I. DESCRIPTIVE STATISTICS FOR THE ELEMENTS ASSESSMENT.

Do you consider what you know about design product process to be foundational knowledge?

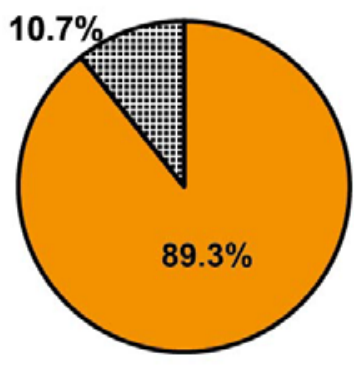

Which phase of the design product process can ET technology have a strategic impact?

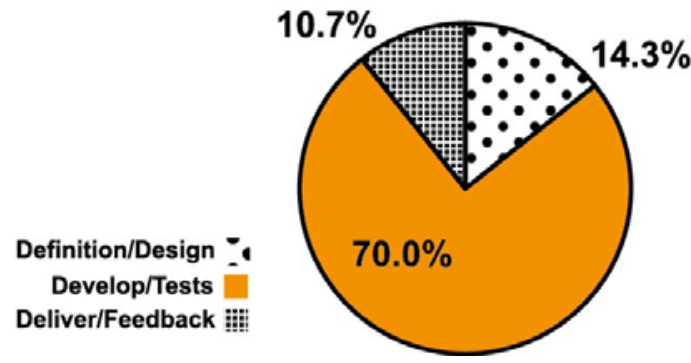

Do you believe the use of ET technology reinforces the design product process?

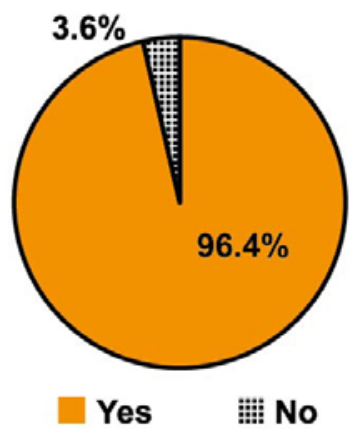

Would you recommend employing ET technology in future design product processes?

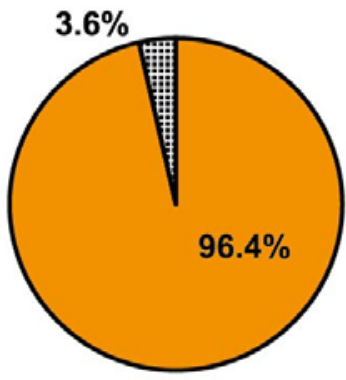

Fig. 5. Percentages for questions regarding students’ opinion on their experiences. 


\begin{tabular}{|c|c|c|}
\hline Perception elements & Mean & Std. Dev. \\
\hline $\begin{array}{c}\text { How do you evaluate the utility of ET } \\
\text { technology used in the course? }\end{array}$ & 4.96 & 0.189 \\
\hline $\begin{array}{c}\text { How do you evaluate the novelty of } \\
\text { ET technology used in the course? }\end{array}$ & 4.86 & 0.448 \\
\hline $\begin{array}{c}\text { How do you evaluate the relevance of } \\
\text { ET technology used in the course? }\end{array}$ & 4.89 & 0.315 \\
\hline
\end{tabular}

\section{DISCUSSION}

This study is the beginning of a series of observations examining how ET technology impacts areas of design education. This paper focused on observing the experience and perception of industrial design students to improve the attraction and engagement using technology and research dynamics. Based on the results of this work, which focused on the use of eyetracking as a key teaching tool, our study can provide answers to the proposed research questions.

RQ1: How can a design and ET project cultivate more interest in research and technology? the findings reveal the students' positive opinion of the project's implementation. Students have a highly positive opinion (96.4\%) of the use of ET as reinforcement in the design process. Also, students primarily believed that ET technology had a major strategic impact on Develop/Test phase (70.0\%) more than the Definition/Design (14.3\%) and Deliver/feedback (10.7\%) phases. Finally, the students expressed their opinion about the duality that a design process must have between a creative and an objective process. They said both (71.5\%). Although, a smaller percentage said they should be a more objective process (25\%). RQ2: How is the acceptance of ET technology in a product design project? The students showed a positive (96.4\%), interest in utilizing ET technology in future design product processes. Finally, this work aimed to display the students' perception of utility, novelty and relevance of ET technology in their projects through two particular questions on the survey.

The statistical results revealed two significant results in regard to RQ3: How do students evaluate the utility, novelty and relevance of ET technology in their projects? First, for the question relating to the utility factor, "Which phase of the design product process can ET technology have a strategic impact?", 21 of the students rated "Develop/Tests” with the highest value of the Likert scale $(M=5.0)$, leaving the other options with no significant consideration. The factors for novelty (M=4.85) and relevance $(\mathrm{M}=4.90)$ were positively qualified, but no significant indicator was observed. Second, a similar effect is observed for the question, "Do you consider that a design product process should implement an objective phase more than a creative phase for create better products?", which relates to the relevance factor. Between the three options, a total of 20 students answered BOTH $(M=4.95)$, leaving YES $(M=4.86)$ and NO $(M=4.00)$ with no significant consideration. In contrast to the discussion on the previous question, the YES and BOTH responses represent an interesting effect because a small percentage of the students identified the objective process with ET technology by presenting a high evaluation on the utility (Myes=5.00) and novelty (Myes=5.00) factors. Even so, most students consider the objectives and creative process with ET to have utility (Mboth=5.00) and novelty (Mboth=4.85) factors as well.

These findings show how students' perceptions of this project were positive. The designed methodology for the project improved interest in research and technology implications. Positive effects in students can be observed. The reception of the ET technology and its processes of evaluating products was well received. The students reflected on the relevance in the product design processes as the objective processes supported by ET technology. Although, the ET technology is not new, the pedagogical application is novel, useful and relevant according to the opinion of the students. The results of this work open the discussion on the use of this type of technology, which allows the creation of dynamics focused on a systematic process and a way of approaching a creative problem. This approach coincides with the vision that some authors have [3-5] regarding experiential practices in laboratories as well as the relationship between analysis and reflections on product design. During the project time, the students could apply dynamics that they had not done before. The use of technology entails a particular way of approaching and analyzing a product, bringing students closer to understanding the relevance of product and service research, now observing the implications that deep research can have on emotional, affective and cognitive determinants that a product design can arouse [12-13].

\section{CONCLUSION}

The results of this work allow us to reflect on novel strategies for incorporating technology into the design product process as a powerful tool for research and the validation of creative process results. The design project of a tool board was a pretext for industrial design students to live systematic thinking in addition to familiar creative processes. However, other projects can be implemented knowing the capacity of ET technology in design validation. An experiential moment captured during the project was how the novel ET process became familiar to the students, even if they were the first-time users of ET technology. This work displayed how technology can become a fundamental part of the design process and how to guide students to integrate rigid and meticulous processes into designing products. Lastly, the overall approval of the project was high, and it motivated the students to investigate the various aspects of design more in depth as well as the functionality of other unclear design processes. 
TABLE II. DESCRIPTIVE AND STATISTICAL RESULTS FOR ASSESSMENT FACTORS BY OPINION.

\begin{tabular}{|c|c|c|c|c|c|c|}
\hline Perception of factors by question & Answers & $\mathbf{N}$ & Mean & Std. Dev. & $\mathbf{F}$ & $\begin{array}{c}\text { Sig } \\
\text { (Anova) }\end{array}$ \\
\hline \multicolumn{7}{|c|}{ Which phase of the design product process can ET technology have a strategic impact? } \\
\hline How do you evaluate the utility of & Exploration/Ideation & 4 & 4.75 & 0.250 & \multirow{3}{*}{3.571} & \multirow{3}{*}{0.043} \\
\hline \multirow[t]{2}{*}{ ET technology used in the course? } & Develop/Tests & 21 & 5.00 & 0.000 & & \\
\hline & Deliver/Feedback & 3 & 5.00 & 0.000 & & \\
\hline \multirow{3}{*}{$\begin{array}{l}\text { How do you evaluate the novelty of } \\
\text { ET technology used in the course? }\end{array}$} & Exploration/Ideation & 4 & 4.75 & 0.500 & \multirow{3}{*}{0.252} & \multirow{3}{*}{0.779} \\
\hline & Develop/Tests & 21 & 4.86 & 0.478 & & \\
\hline & Deliver/Feedback & 3 & 5.00 & 0.000 & & \\
\hline \multirow{3}{*}{$\begin{array}{l}\text { How do you evaluate the relevance of } \\
\text { ET technology used in the course? }\end{array}$} & Exploration/Ideation & 4 & 4.75 & 0.500 & \multirow{3}{*}{0.581} & \multirow{3}{*}{0.566} \\
\hline & Develop/Tests & 21 & 4.90 & 0.301 & & \\
\hline & Deliver/Feedback & 3 & 5.00 & 0.000 & & \\
\hline \multicolumn{7}{|c|}{ Do you think a design product process should be more an objective process or a creative process in order to create better products? } \\
\hline \multirow{3}{*}{$\begin{array}{l}\text { How do you evaluate the utility of } \\
\text { ET technology used in the course? }\end{array}$} & Yes & 7 & 5.00 & 0.000 & \multirow{3}{*}{0.000} & \multirow{3}{*}{1.000} \\
\hline & Both & 20 & 5.00 & 0.000 & & \\
\hline & No & 1 & 4.00 & 0.000 & & \\
\hline \multirow{3}{*}{$\begin{array}{l}\text { How do you evaluate the novelty of } \\
\text { ET technology used in the course? }\end{array}$} & Yes & 7 & 5.00 & 0.000 & \multirow{3}{*}{2.414} & \multirow{3}{*}{0.110} \\
\hline & Both & 20 & 4.85 & 0.0489 & & \\
\hline & No & 1 & 3.57 & 4.00 & & \\
\hline \multirow{3}{*}{$\begin{array}{l}\text { How do you evaluate the relevance of } \\
\text { ET technology used in the course? }\end{array}$} & Yes & 7 & 4.86 & 1.299 & \multirow{3}{*}{6.028} & \multirow{3}{*}{0.007} \\
\hline & Both & 20 & 4.95 & 1.345 & & \\
\hline & No & 1 & 4.00 & 0.000 & & \\
\hline
\end{tabular}

The authors would also like to acknowledge the financial support provided by the Novus grant (Laboratorio de diseño, exploración y validación de productos y espacios), PEP No. PHHT002_18ZZ00041, as well as the support of the Writing Lab and TecLabs at Tecnologico de Monterrey, Mexico, throughout the production of this work.

\section{REFERENCES}

[1] A. Findeli, "Rethinking Design Education for the 21st Century: Theoretical, Methodological, and Ethical Discussion,” Design Issues, vol. 17 (2001): pp. 517. DOI: $10.1162 / 07479360152103796$

[2] B.H. Banathy, "Systems thinking in higher education: learning comes to focus," Systems Research and Behavioral Science, vol.16, No. 2 (1999): pp.133. DOI: 10.1002/(SICI)1099-1743(199903/04)16:2<133::AID-SRES281>3.0.CO;2-T

[3] L. Trevisan, P.P. Peruccio, and S. Barbero, “From engineering to industrial design: issues of educating future engineers to systemic design,” Procedia CIRP, vol. 70 (2018): pp.319-324. DOI: 10.1016/j.procir.2018.02.014

[4] M.T. Greene, R. Gonzalez, P.Y. Papalambros, and A.-M. McGowan, “Measuring Systems Engineering and Design Thinking Attitudes.” ICED International Conference on Engineering Design, vol. 1, pp. 3939-3948, July 2019. DOI: 10.1017/dsi.2019.401

[5] R. Oxman, “Think-maps: teaching design thinking in design education,” Design Studies, vol. 25, no. 1 (2004): pp. 63.91. DOI: 10.1016/S0142694X(03)00033-4

[6] E. Francalanza, J. Borg, A. Fenech, and P. Farrugia, “Emotional Product Design: Merging industrial and engineering design perspectives,” Procedia CIRP, vol. 84 (2019): pp. 124-129. DOI: :10.1016/S0142-694X(03)00033-4

[7] C. Wölfel, "How industrial design knowledge differs from engineering design knowledge,” E\&PDE the 10th International Conference on Engineering and Product Design Education, vol. 1, pp.222-227, September 2008.

[8] J. Hoffman, and B. Subramaniam, “The role of visual attention in saccadic eye movements,” Perception \& Psychophysics, vol. 57 (1995): pp.787-795. DOI: 10.3758/BF03206794

[9] C. Spence, and J. Driver, Crossmodal Space and Crossmodal Attention. Oxford: Oxford University Press, 2004.

[10] Y. Pertzob, G. Avidan, and E. Zohary, “Accumulation of visual information across multiple fixations,” Journal of Vision, vol. 9 (2009): pp.103582. DOI: $10.1167 / 9.10 .2$

[11] T. Ben-Bassat, “Are ergonomically designed road signs more easily learned?” Applied Ergonomics, vol. 78 (2019): pp. 137-147. DOI: 10.1016/j.apergo.2019.02.009

[12] G. Feberico, and M.A. Brandimonte, “Tool and object affordances: an ecological eye-tracking study,” Brain and Cognition, vol. 135 (2019): pp. DOI: 10.1016/j.bandc.2019.103582

[13]E. Ambrosini, and M. Costantini, "Body posture differentially impacts on visual attention towards tool, graspable, and non-graspable objects," Journal of Experimental Psychology: Human Perception and Performance, vol. 43, No. 2 (2017): pp. 360-370. DOI: 10.1037/xhp0000330

[14] M.K. Eckstein, B. Guerra-Carrillo, A.T. Miller Singley, and S.A Bunge, "Beyond eye gaze: What else can eye-tracking reveal about cognition and cognitive development?” Developmental Cognitive Neuroscience, $\quad$ vol. 25 (2017): pp. $\quad 69-91 . \quad$ DOI: 10.1016/j.dcn.2016.11.001 
